\title{
TERESA DE ÁVILA: DOUTORA, MÍSTICA E PROTO-FEMINISTA EM ÉPOCAS DE DOGMATISMOS CRISTÃOS
}

Yvisson Gomes dos Santos ${ }^{1}$

RESUMO: O presente ensaio tem como finalidade mostrar a Santa Teresa de Ávila ou de Jesus, como fora conhecida, através da óptica de seus escritos, bem como da psicanálise com a feminilidade como possibilidade de interlocução. Apontar o estabelecimento da (a)lógica da mística cristã até o possível advento do feminismo, na tentativa, mesmo que propedêutica, da Santa Doutora com fios que a ligavam a uma atitude diacrônica proto-feminista pelos seus feitos e vasto volume de escritos doutorais à sua época na Espanha Católica.

PALAVRAS-CHAVE: Teresa de Jesus, feminilidade, feminismo, psicanálise.

ABSTRACT: The purpose of this essay is to show Saint Theresa of Avila or Jesus, as she was known, through the perspective of her writings, as well as of psychoanalysis with femininity as a possibility of interlocution. To point out the establishment of the logic of Christian mysticism until the possible advent of feminism, in the attempt, even if propaedeutic, of the Holy Doctor with threads that linked her to a proto-feminist diachronic attitude for her achievements and a vast volume of doctoral writings his time in Catholic Spain.

KEYWORDS: Teresa de Jesus, femininity, feminism, psychoanalysis.

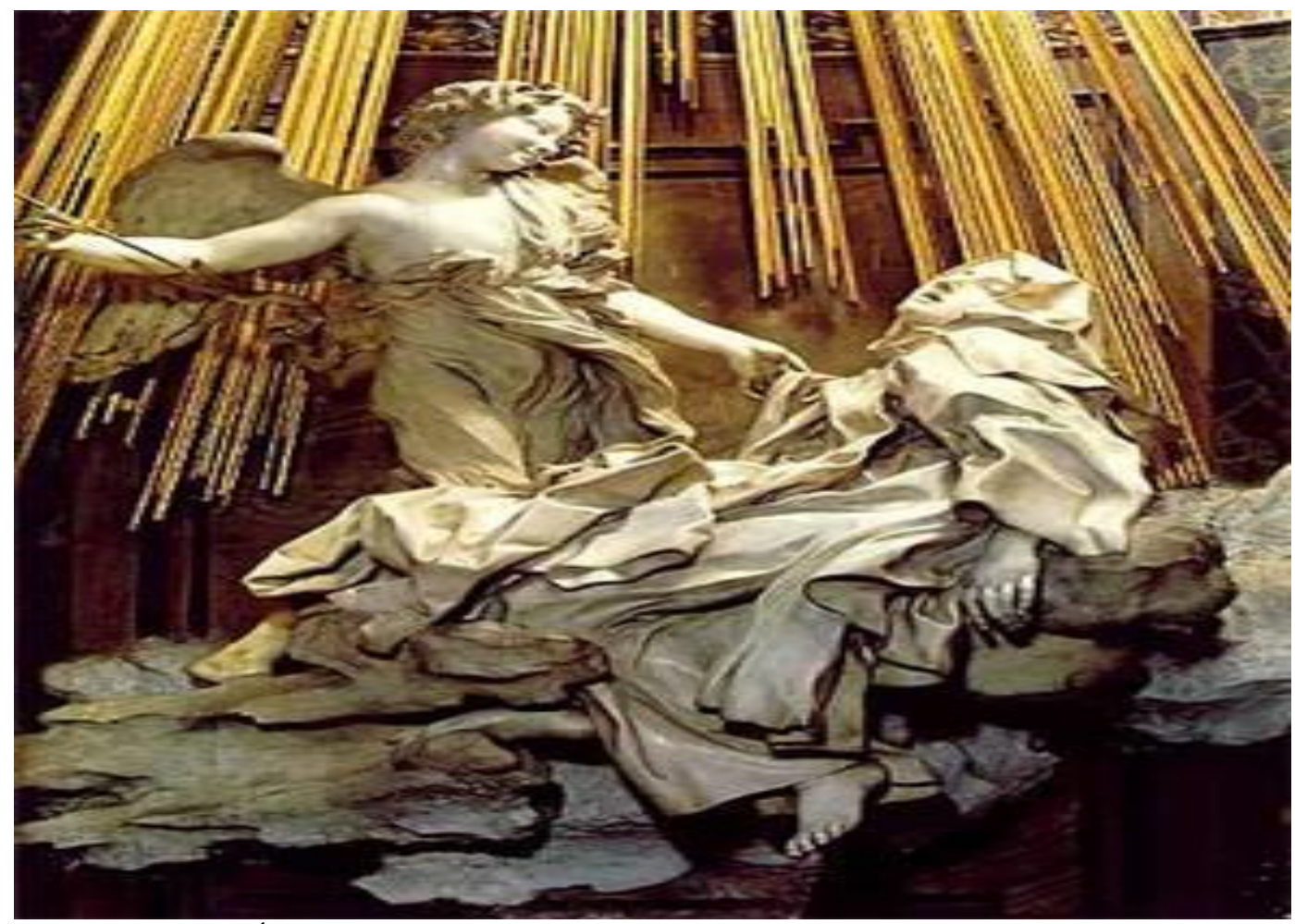

Escultura da Santa de Ávila por Bernine - (http://thiagof-amorim.blogspot.com/2012/12/o-extase-de-santateresa.html)

\footnotetext{
${ }^{1}$ Doutorando em Educação pela Universidade Federal de Alagoas, E-mail: yvissongomes@hotmail.com
} 
É possível que com o passar dos anos, dos séculos, alguma coisa se modifique em nossa mente, algo que o tempo pode ora obscurecer, ora clarificar, colocando certos preceitos/conceitos muitas vezes no umbral do esquecimento. Contudo, existe a possibilidade de um retorno, tal como Freud (1988) preconizava, um retorno do recalcado que o tempo não consegue dirimir.

Teresa de Ávila, doutora da Igreja, pode ser uma mulher que o tempo não à fez esquecer, reverberando uma história de grandes feitos, no qual a Santa, flechada de um dardo ardente em fogo, tal como na escultura de Bernine, continua viva, atual e pronta a se movimentar de seu antigo lugar seiscentista para a modernidade.

O que se quer falar quando se fala de Teresa? Em qual lugar a Santa se encontra no traçado epistemológico da atualidade? E um pouco a mais, um excesso, o que a psicanálise pode dizer sobre a mística teresiana?

Nascida Teresa Sánchez de Ahumada em 28 de março de 1515, em Ávila, com ascendência nobre por parte materna, em oposição à "duvidosa linhagem paterna" que provia de judeus, transformados em cristãos-novos pela então Igreja reinante -, esse era o traçado filial da menina espanhola. Época de grandes transformações sócio-culturais, econômicas e principalmente religiosas. Estamos falando do movimento da Contra-Reforma, uma iniciativa forjada pela igreja em manter sua autoridade suprema na luta contra os reformados, os protestantes desde Lutero, a Calvino, ao rei inglês Henrique VIII, dentre outros (STRAUSZ [S.D.]; ROSSI [1988])

Teresa nasceu nesse universo de disputas acirradas pelo poder, no qual não se podia ouvir a voz divina, pois tudo seria ameaça aos costumes da autoridade de um tempo que possuía a florilegia e libri proverbionrum. Mesmo assim a menina de Ávila sonhava em ser mártir, e desde o momento de sua entrada na Ordem das Carmelitas deu-se uma mudança em sua vida que viria a ser um paradigma aos futuros santos e beatos, a saber, o êxtase místico.

Em sua entrada na vida religiosa não se deve deixar de pontuar que a recém postulante ao mosteiro atraia olhares. Teresa era bela, possuía uma sedução impar aos seus pares, bem como aos fidalgos que a visitavam quinzenalmente no momento de trocas de favores que o mosteiro da Encarnação tinha. Trocas de orações das irmãs às famílias aristocráticas que vinham em busca de alívio, em contrapartida a favores financeiros que estas mesmas famílias prestavam a estância religiosa.

Temos dois elementos textuais que vão se definindo: o primeiro, o êxtase místico e o segundo a beleza/sedução de Teresa de Ávila. Como entender então o êxtase apontado aqui nesse ensaio?

É de nota que o êxtase provém do deus grego Dioniso. As Bacantes (2011), de Eurípedes, eram personagens que vociferavam entre o real e o imaginário. Destroçavam animais com barbárie e 
embriagadas com o vinho retorciam pescoços, mãos, flancos num frenesi único, lancinante. O étimo diz: "Ek-stase indicando estar fora de si, fixidez, imobilidade" (LAROUSSE, 1992, p. 145). Decerto o êxtase provia de algo que dominava aquele que o possuía.

A loucura se estabelecia para quem estava ébrio de Dioniso ou Baco, as formas dionisíacas de Nietzsche, em seu livro inaugural, nos diz desse mundo avernal que o que predomina é a insanidade, o pré-logicismo e o gozo (NIETZSCHE, 1992).

Pode-se dizer que Teresa gozava no sentido de que algo irracional espraiava em sua realidade psíquica. Gozo este que reclama prazer e dor, contextualizado na psicanálise como elemento que descreve um dos significantes do inconsciente, aquilo que se direciona a um objeto desejado, na fala, no fora-texto, a Outro ${ }^{2}$. E que Outro seria esse de Teresa? O Deus de Teresa!

Em alguns de seus poemas fica-se com a impressão de que esse Deus subscreve-se pela ordem do Real, dando um sentido que evoca a palavra como sendo fator axial para se tentar dizer aquilo que não se pode dizer. Ei-lo:

Porque tu eres mi aposento/eres mi casa y morada,/Y asi llamo em cualquier tiempo,/Si hallo em tu pensamiento/Estar La puerta cerrada”. E em outro momento: "Haz, Señor, que acabe/Tan larga agonia;/Socorre a tu sierva/Que por ti suspira./Rompe aquestos hierros/Ysea feliz./Ansiosa de verte,/deseo morir (JESUS,2002, p.990, grifo nosso).

Estamos vendo uma mulher que "falava" com Deus e que com ele gozava numa relação de quase morte - "desio morir" - pois o gozo pode ser também traduzido como pequena morte, ou em francês petit mort.

Partindo desse pressuposto de um Deus que fala e de uma ouvinte, a Igreja repreendeu esses "enlaces místicos" da Santa colocando-a sob atenção de frades dominicanos e franciscanos que deveriam catequizar e dissuadir as ideias que pairavam em sua mente. Algumas de suas obras foram modificadas e trechos deixaram de existir. Ela seguia fiel aos princípios de seus superiores.

O que convêm lembrar é de que essa mulher ultrapassava os limites culturais de sua época e demonstrava uma desmesura, a hybris, algo inerente à feminilidade (LACAN, 1993) . Desde a sua passagem pelo Carmelo, ela conseguiu criar um novo modo de vida as suas irmãs religiosas. Fundou a Ordem Carmelita Descalça com características mais rígidas e contemplativas, dominando grande parte da Espanha e tendo o aval de nobres e do próprio Papa para revolucionar, na sua época, o pensamento

\footnotetext{
${ }^{2} \mathrm{O}$ significado da palavra Outro (em maiúscula) diz do "lugar onde a psicanálise situa, além do conceito imaginário, aquilo que, anterior e exterior ao sujeito, não obstante o determina." (CHEMAMA, R. Dicionário de Psicanálise. Trad. Franke Sttineri. Porto Alegre: Artes Médicas Sul, 1995, p. 156).
} 
cristão. Teresa de Ávila criou uma forma de relação diplomática com o Vaticano que poderia ser pensada em uma mulher que dominava o mundo católico a sua volta, não deixando de viver uma vida asceta, porém com trocas simbólicas importantes entre seus superiores e sua própria existência.

Falar sobre a sedução e beleza de Teresa de Ávila ainda nos mostra uma possível atualidade entre "aquilo que margeia o furo", no dizer de Pommier (1987, p. 25) pois a beleza tem suas particularidades. Falamos aqui da Estética. Sem nos alongar: a estética diz-se da forma do que se apresenta aos olhos e aos sentidos. A beleza comunga da estética, ou seja, é uma extensão da mesma. Há o prazer, a fruição que é despertada na sensibilidade do homem ao se encontrar com uma obra de arte, por exemplo; da mesma forma com o conhecimento sensorial, sensível que essa mesma obra de arte pode despertar em alguém que o veja.

Teresa compunha a beleza, de que muitos fidalgos desejavam. E ademais estava entranhada com a sedução, - elemento inerente ao feminino -, bem como às primeiras fases do desenvolvimento psicosssexual do homem. Graças à palavra que se fez carne, os escritos da monja se sobressaíram ao seu contexto social reinante. Ela se colocou como uma porta voz da mulher frente ao poderio masculino, decididamente como, a meu entender, uma proto-feminista que já fazia voz em épocas medievas.

Com isso se diz que A Mulher, no sentido geral do termo, ainda que passada pela interdição como tendo um A (maiúsculo) barrado, lembrando-nos aqui de Lacan (1993), ainda assim, essa monja-mulher predominou no seu tempo como uma personagem que conseguiu mostrar que a força do dito sexo frágil não era tão frágil assim. Temos uma iniciadora da alteridade feminista numa época, vale relembrar, de intensa "escuridão" cultural e negação do sujeito-feminino.

Quando salientamos que a modernidade contribuiu e muito com os avanços da subjetividade feminina queremos dizer que Teresa de Ávila em seu tempo e contexto social próprios foi uma desbravadora da consciência de que a mulher, mesmo sendo enclausurada e monja, pôde conseguir uma voz, um reclame que contribuiu em uma alteridade imprescindível do que é ser feminino anteposto ao que é ser masculino (um binarismo letal).

O que caracterizou os movimentos feministas das décadas de 1960, em diante, era a igualdade dos sexos, aquilo que era para ser do homem era para ser da mulher. O que a psicanálise vem a contribuir com isso é de que jamais haverá igualdade entre os sexos, pois os mesmos têm suas particularidades que são intrínsecas a cada um. Acreditando nisso, pensa-se em Teresa. Ela como mulher era diferente do sexo oposto, mas com sua autoridade e equilíbrio conseguiu criar mais de 10 mosteiros e ser uma mulher que se encontrava atualizada em sua realidade, compreendendo que o outro (semelhante) tinha suas distinções e particularidades. 
Teresa de Jesus conseguiu, na linha de pensamento que se traça com a psicanálise, a partir do diferente, construir uma concepção feminista, não unívoca, mas polifônica. Ela conseguiu resvalar a pseudo-inutilidade da mulher medieval que estava fadada ao analfabetismo e exclusão social e construiu uma identidade própria, um estilo teresiano de ser.

Com essas referências, pode-se dizer que Teresa de Jesus ou de Ávila, demonstrou em sua vida e escritos o que viria a ser séculos depois uma gênese do movimento feminista.

Em suas cartas ela testificava o amor a Deus, aos seus confessores, porém não deixando de enfatizar que quando Deus ama aos seus filhos, Ele o quer disseminador da Sua palavra de uma forma coerente e enfática. Nessas cartas, uma em especial ao licenciado Dionisio Luiz de La Peña, Tereza deixa claro que concorda com os desígnios de Deus à sua vida, porém no termino diz: "Indignada serva e súdita de vossa Reverência. Quão de boa vontade o digo!” (JESUS,2002, p. 1123)

\section{REFERÊNCIAS}

CHEMAMA, R. Dicionário de Psicanálise. Trad. Franke Sttineri. Porto Alegre: Artes Médicas Sul, 1995.

EURÍPIDES. As Bacantes. Tradução de Eudoro de Sousa. São Paulo: Hedra, 2011.

FREUD, Sigmund. Além do princípio do prazer. Rio de Janeiro, Imago, 1988.

JESUS, Teresa de. Obras Completas. São Paulo: Edições Loyola. 2002.

LACAN, Jacques. Seminário XX. Mais, ainda .Rio de Janeiro, Zahar Editor 1993

LAROUSSE. Dicionário de Língua Portuguesa. São Paulo: Nova Cultural LTDA, 1992.

NIETZSCHE, Friedrich. O Nascimento da Tragédia: ou helenismo e pessimismo. Tradução: J. Guinsburg. São Paulo: Companhia das letras, 1992

POMMIER, Gerard. A exceção feminina: os impasses do gozo. Rio de Janeiro: Jorge Zahar Editor Ltda, 1987.

ROSSI, Rosa. Teresa de Ávila: biografia de uma escritora. Rio de Janeiro: José Olympio, 1988.

STRAUSZ, Rosa Amanda. Teresa de Ávila: a Santa apaixonada: São Paulo: Objetiva, [s.d].

Recebido em: 18/03/2018

Aprovado em: 11/04/2018

Publicado em: 01/07/2018 